
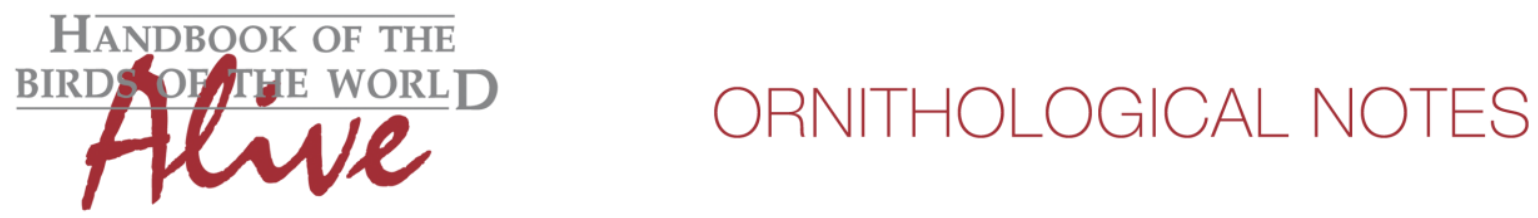

\title{
Notes on the vocalizations of White-browed Shortwing (Brachypteryx montana)
}

Peter Boesman

In the following we briefly analyze and compare voice of the different races of White-browed Shortwing (Brachypteryx montana). We also try to quantify the extent of any vocal differences using the criteria proposed by Tobias et al. (2010), as a support for taxonomic review. We have made use of sound recordings available on-line from Xeno Canto (XC).

Song of $B$. montana shows significant variation over its extensive range. An overview of song per race with some examples (supported by more similar recordings for every race, unless mentioned otherwise):

cruralis (Himalayas):

'Typical' song: some intro notes at about flat pitch followed by a warbled phrase

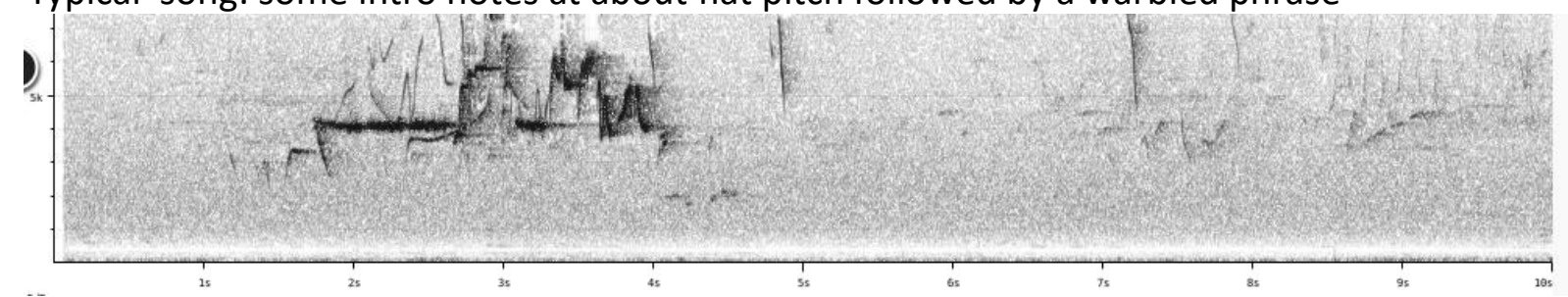

but sometimes inversed with long note at end, or lacking:

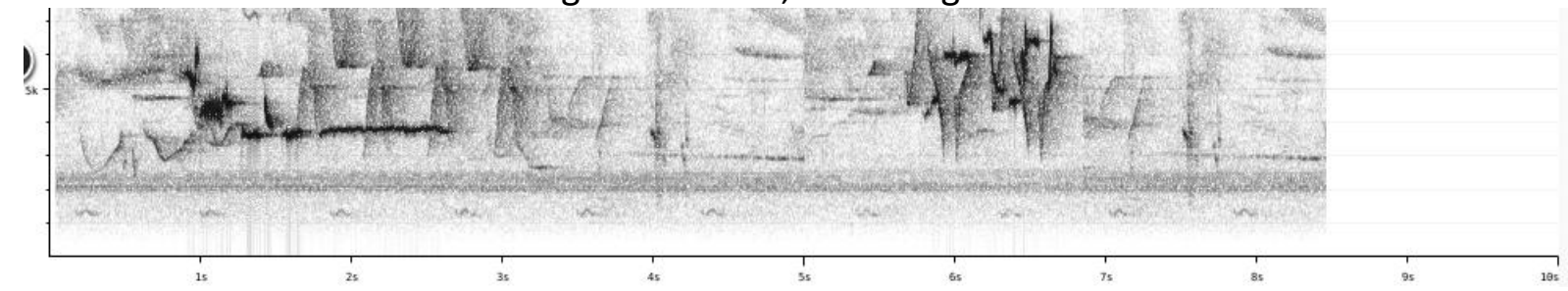

sinensis (C \& SE China):

Typical song is a short phrase with few notes, starting with a fairly short note at flat pitch. Differs from cruralis in shorter phrase length and lower number of notes (less warble).

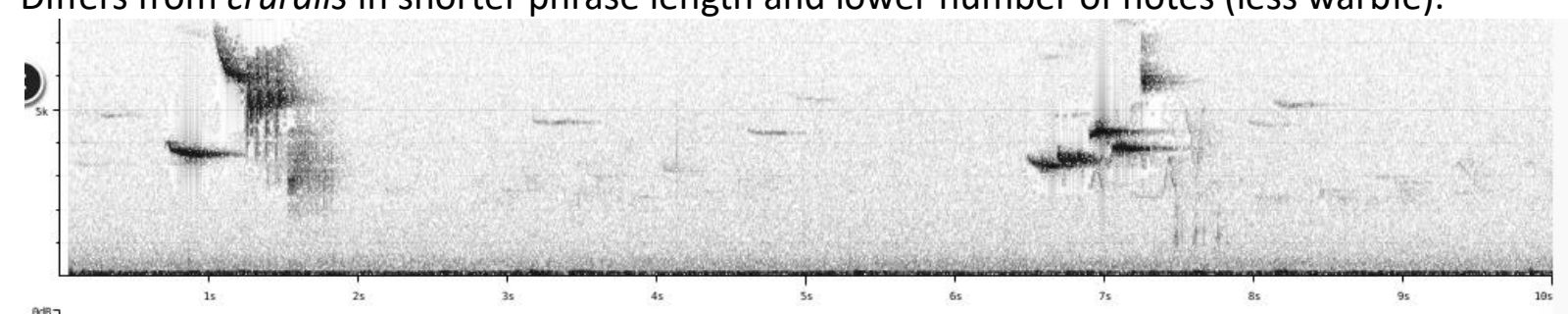




\section{HANDBOOK OF THE

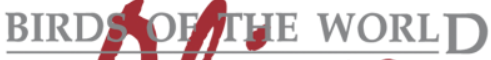 \\ Aluve}

\section{ORNITHOLOGICAL NOTES}

goodfellowi (Taiwan):

Typical song is a short phrase, starting with a fairly short note at flat pitch. Very much like sinensis (probably not safely told apart).

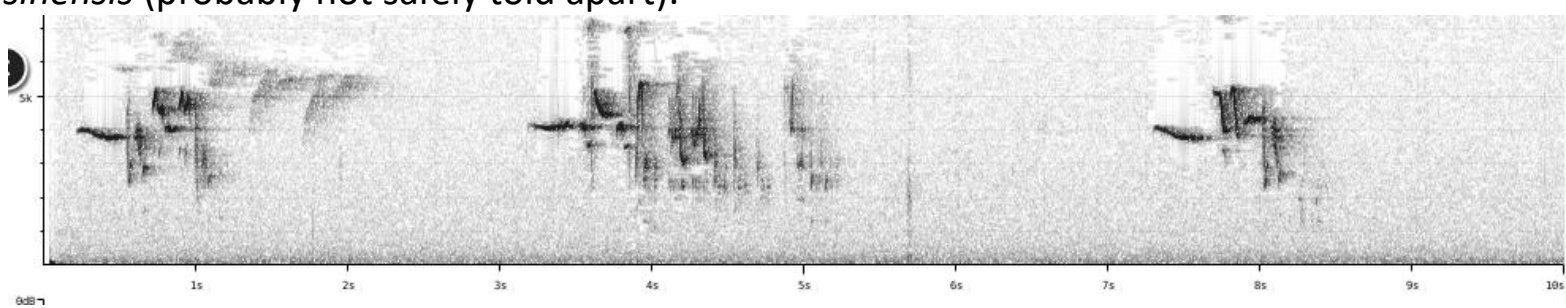

saturata (Sumatra):

Typical song is very different from above races: a long phrase of short staccato notes going up and down the scale many times, gradually increasing in volume.

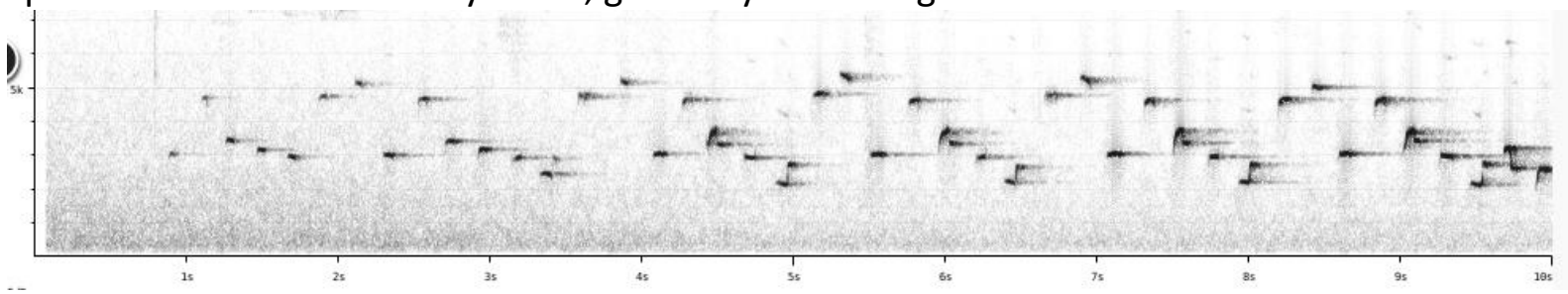

montana (Java):

Typical song is a pleasant leisurely-delivered melodious song phrase, at rather stable pitch (all notes typically between $2 \mathrm{kHz}$ and $4-4.5 \mathrm{kHz}$ ). Irregular pauses and longer phrases alternated by shorter ones. Has longer, more flute-like notes than saturata (2) and notes don't show an up-and-down repetitive pattern (1-2), with narrower frequency range (1-2). Phrase lengths shorter (3) and no gradual build-up of amplitude (2). Total score vs. neighbour saturata about 5.

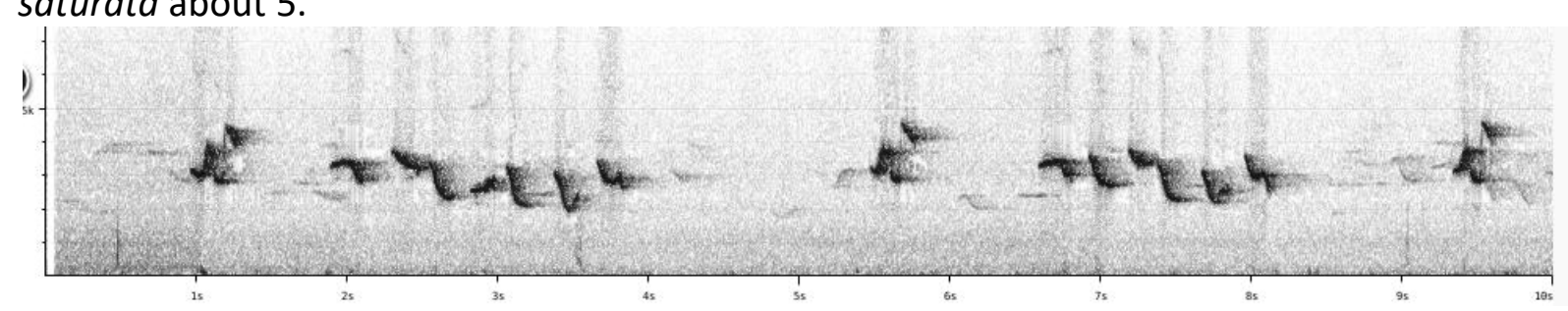

erythrogyna (Borneo):

Song has more flute-like notes than saturata with a somewhat similar up-and-down the scale structure but lacking a clear repetitive pattern, vocally closer to saturata than montana.

Differs from montana by longer song phrase (score 2-3) and larger frequency range reaching higher frequencies (c. $7 \mathrm{kHz}$ ) (score 2-3).

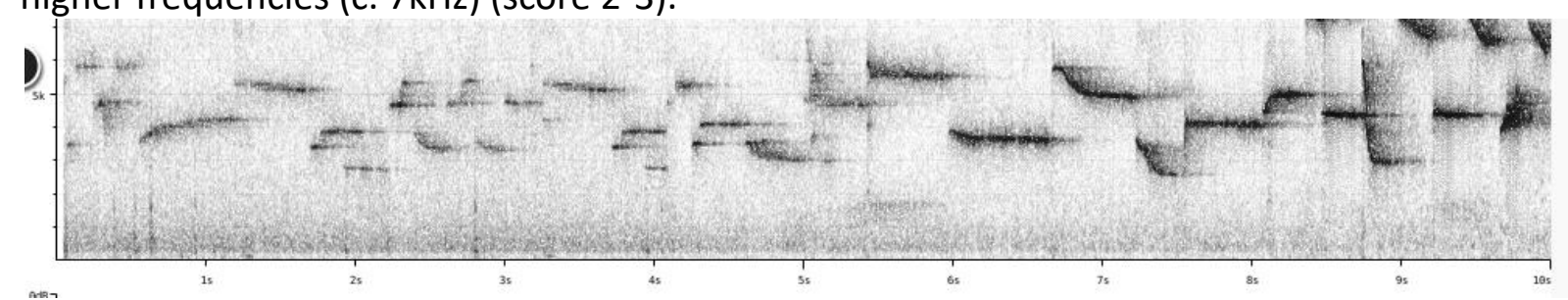




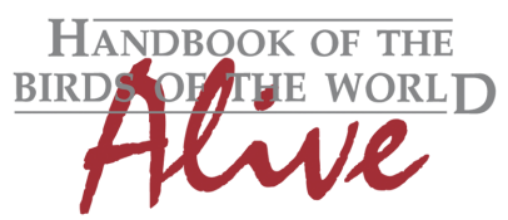

\section{ORNITHOLOGICAL NOTES}

mindanensis (Mindanao, Philippines):

Typical song is very peculiar, quite unlike any other race, starting with a long series of repeated notes, gradually increasing in volume, and continuing with many repeats. A long phrase!

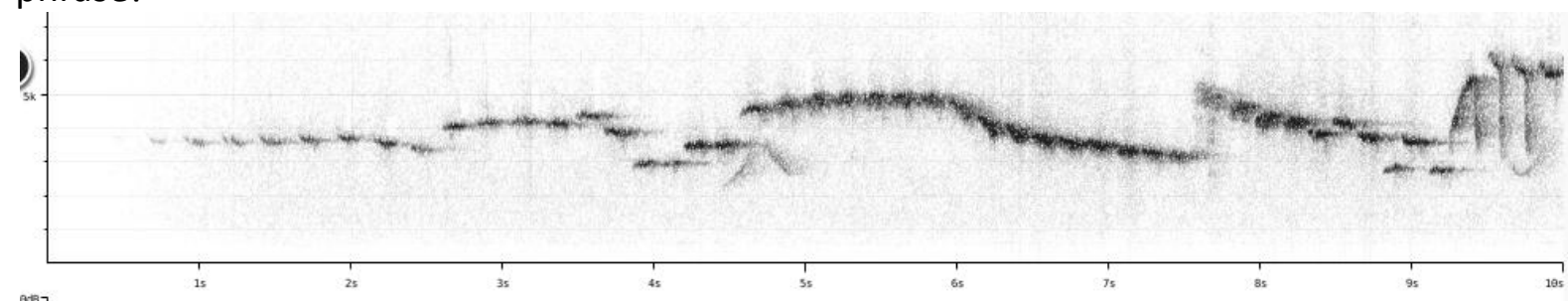

brunneiceps (Negros \& Panay, Philippines):

Song is quite different from its more southern neighbour mindanensis. Only a few recordings available and seems to have two song types, a simple 2 notes repeated and a more complex warbling song. Not closely resembling any of the above races, but neither showing specific characteristics.

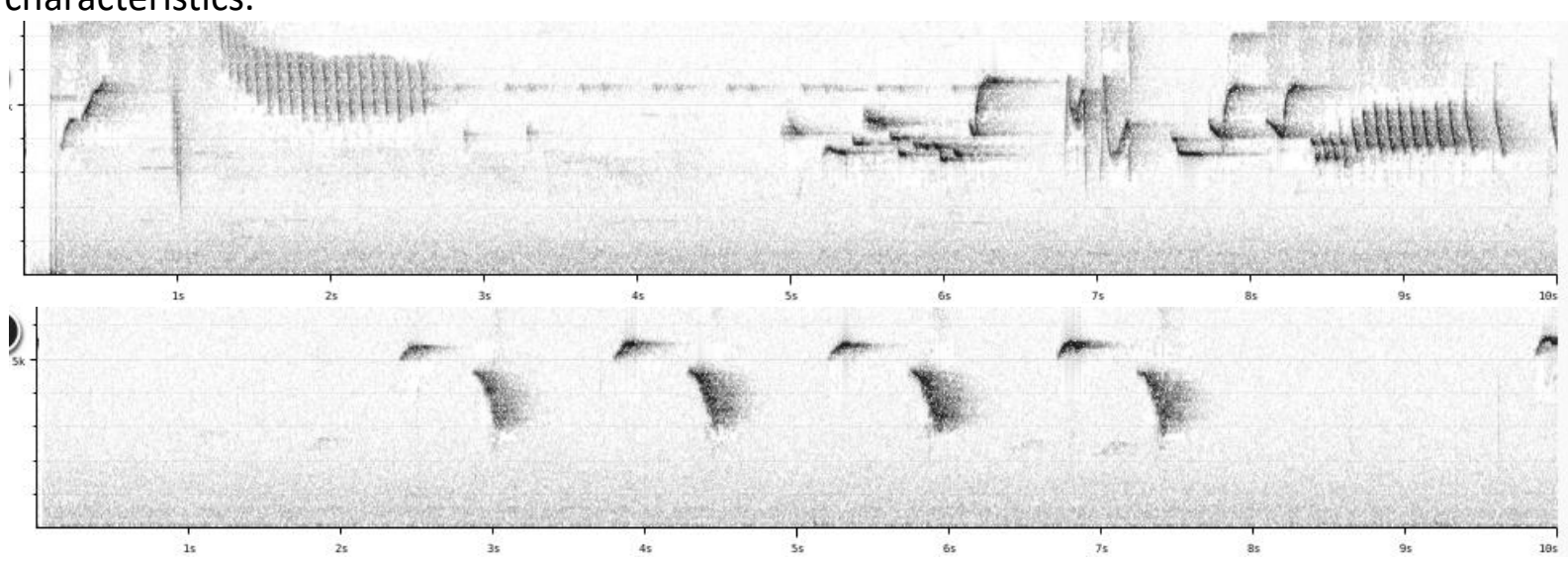

poliogyna (Luzon, Philippines):

Song is a leisurely delivered whistled phrase, not unlike montana, but whistled notes have a very eerie trembled quality, which separates this song type from any other race.

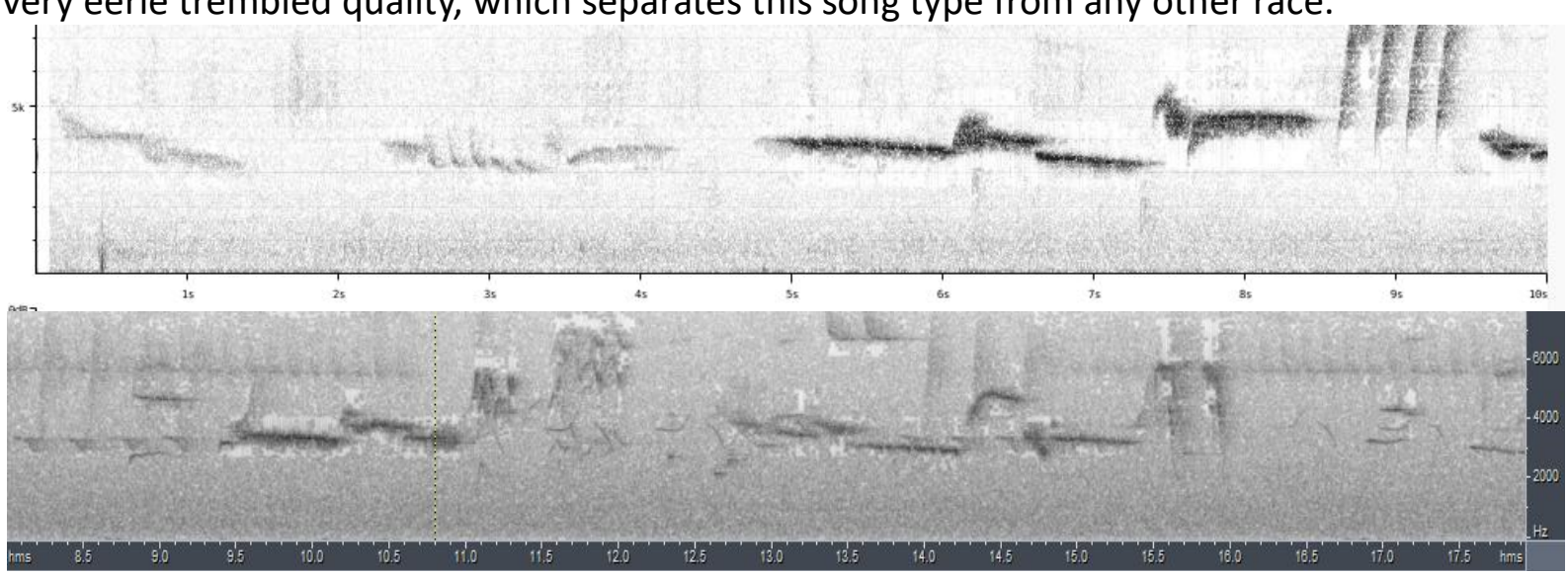

At closer inspection these trembling notes seem to be fast repeats of identical notes:

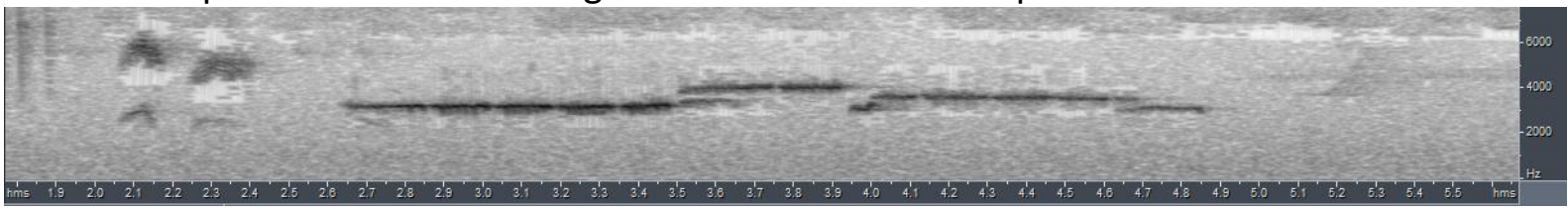



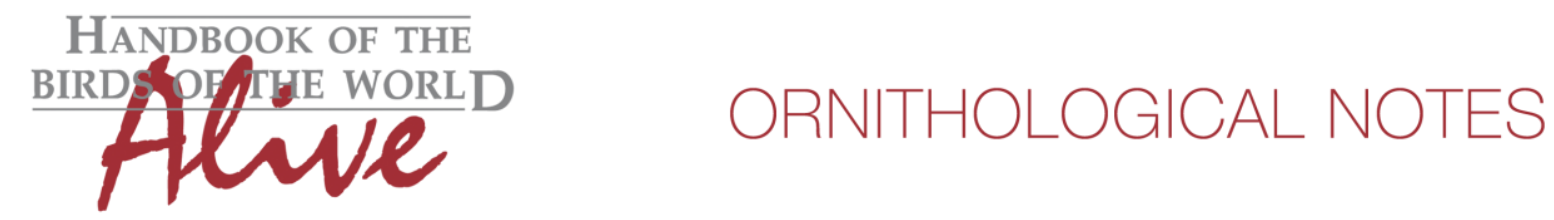

floris (Flores, Indonesia):

We have only 2 recordings available of song, which don't allow to draw any firm conclusions, but both recordings different from above races:

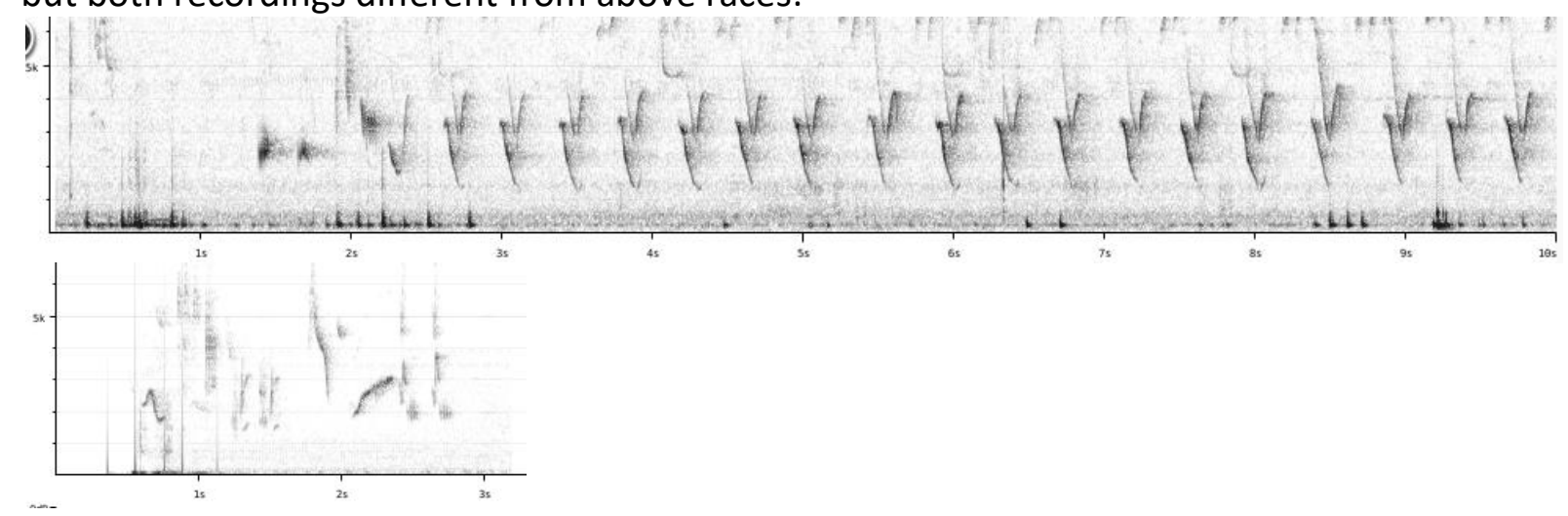

Compared to other races lower frequencies seem to be reached.

There are no recordings available for several additional Philippine taxa (and there is seemingly an additional undescribed taxon on Mindanao with a song different from mindanensis).

From the above, it is clear that this is quite a complex case. There are vocally several fairly distinct groups:

\section{Group 1: cruralis/sinensis/goodfellowi}

Song is a typical robin-like song often starting with an initial whistle, followed by a short melodious phrase, occasionally ending with a more scratchy or rattling part. Within this group, sinensis and goodfellowi are very similar. cruralis somewhat different, with typically a longer song phrase (score 1-2) and on average more notes/phrase (score 1), total score about 2-3.

Group 2: saturata/erythrogyna/montana is a more heterogeneous group:

saturata: song closest to erythrogyna, but still unique by its short staccato bell-like notes going up and down the scale in a repetitive pattern. Score vs. erythrogyna based on note length and repetitive pattern $3+1=4$. Score vs. montana 5 (see above). Score vs.

cruralis/sinensis/goodfellowi based on much longer phrase length (score 3-4), short notes (score 2-3) and high number of notes (3). Total score about 6.

erythrogyna vs Group 1: much longer song phrase (3-4) and much more notes/phrase (score 2-3) total score about 6.

montana vs Group 1: narrower freq. range (score 2) with lower max. freq. (score 3) and slower average pace (score 2). Total score 5.

mindanensis: just like saturata standing apart because of its unique song structure, gradually building up with pulsed note repetitions (score 2) smoothly changing into series with a larger pitch change up and down, resulting in a very long song phrase. Diference vs. Group 1 are the much longer song phrase (3) and higher number of notes (3), vs. group 2 difference less straightforward to quantify, could be expressed e.g. as \# of repeated near-identical notes (score 3 ) and additionally longer song phrase than montana (2), no phrase repeat as in 

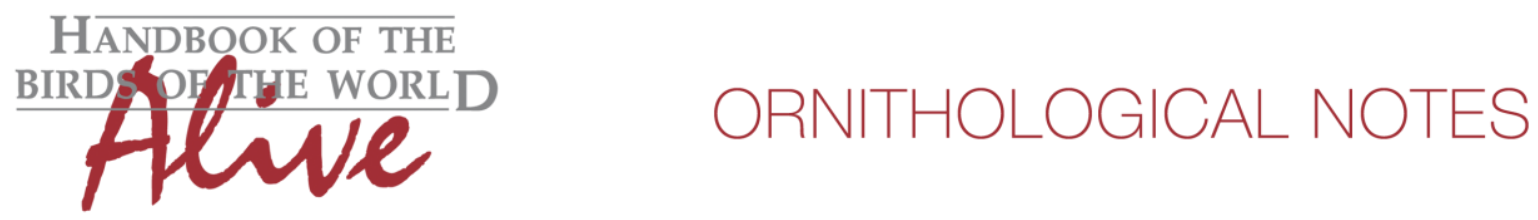

saturata (2).

poliogyna is unique in having long trembled notes which are actually pulsed repeated notes (score 3 vs. all other races, score 2 vs. mindanensis). Phrase length longer than group 1 (2) and shorter than saturata, erythrogyna and mindanensis (score 2-3). Phrase length similar to montana, but differs from this taxon by pace (1-2).

brunneiceps and floris are poorly documented, and only roughly estimated scores can be given:

floris looks quite distinct with low frequency burry notes, and apparently peculiar long repeats of short phrases (estimated score about $4 \mathrm{vs.} \mathrm{other} \mathrm{races).}$

brunneiceps even less clear, given the apparent existence of 2 song types. One song type somewhat similar to erythrogyna, the other rather unique a double note repeated (estimated song score about 4-5 vs. group 1, about 3-4 vs. other races except erythrogyna.

In summary, we get the following score table:

\begin{tabular}{|c|c|c|c|c|c|c|c|c|c|c|}
\hline & montana & erythrogy & runneic & oliogyn & indane & ruralis & sinensis & goodfell & urata & flores \\
\hline montana & - & 5 & $(3-4)$ & 5 & 5 & 5 & 5 & 5 & 5 & (4) \\
\hline erythrogyna & & - & (?) & 5 & 3 & 6 & 6 & 6 & 4 & (4) \\
\hline brunneiceps & & & - & (3-4) & $(3-4)$ & $(4-5)$ & $(4-5)$ & $(4-5)$ & 5 & (4) \\
\hline poliogyna & & & & - & 4 & 5 & 5 & 5 & 5 & (4) \\
\hline mindanensis & & & & & - & 6 & 6 & 6 & 5 & (4) \\
\hline cruralis & & & & & & - & $2-3$ & $2-3$ & 6 & (4) \\
\hline sinensis & & & & & & & - & 0 & 6 & (4) \\
\hline goodfellowi & & & & & & & & - & 6 & (4) \\
\hline saturata & & & & & & & & & - & (4) \\
\hline floris & & & & & & & & & & - \\
\hline
\end{tabular}

All mentioned scores are well-considered estimations, but would obviously benefit from confirmation by a more detailed measurement and quantification of the sound parameters (which was not possible here due to time constraints).

This note was finalized on 22nd June 2016, using sound recordings available on-line at that moment. We would like to thank in particular the many sound recordists who placed their recordings for this species on XC.

\section{References}

Tobias, J.A., Seddon, N., Spottiswoode, C.N., Pilgrim, J.D., Fishpool, L.D.C. \& Collar, N.J. (2010). Quantitative criteria for species delimitation. Ibis 152(4): 724-746. 


\section{Recommended citation}

Boesman, P. (2016). Notes on the vocalizations of White-browed Shortwing (Brachypteryx montana). HBW Alive Ornithological Note 322. In: Handbook of the Birds of the World Alive. Lynx Edicions, Barcelona. (retrieved from http://www.hbw.com/node/1252522 on 20 October 2016). 